This item was submitted to Loughborough's Research Repository by the author.

Items in Figshare are protected by copyright, with all rights reserved, unless otherwise indicated.

\title{
Relational efficacy beliefs in physical activity classes: a test of the tripartite model
}

PLEASE CITE THE PUBLISHED VERSION

http://journals. humankinetics.com/jsep-back-issues/jsep-volume-34-issue-3-june-/relational-efficacy-beliefs-inphysical-activity-classes-a-test-of-the-tripartite-model

\section{PUBLISHER}

(c) Human Kinetics, Inc.

\section{VERSION}

AM (Accepted Manuscript)

\section{LICENCE}

CC BY-NC-ND 4.0

\section{REPOSITORY RECORD}

Jackson, Ben, Nicholas D. Myers, lan M. Taylor, and Mark R. Beauchamp. 2019. "Relational Efficacy Beliefs in Physical Activity Classes: A Test of the Tripartite Model”. figshare. https://hdl.handle.net/2134/15376. 
This item was submitted to Loughborough's Institutional Repository (https://dspace.lboro.ac.uk/) by the author and is made available under the following Creative Commons Licence conditions.

\section{creative
commons}

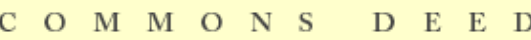

Attribution-NonCommercial-NoDerivs 2.5

You are free:

- to copy, distribute, display, and perform the work

Under the following conditions:

Attribution. You must attribute the work in the manner specified b the author or licensor.

Noncommercial. You may not use this work for commercial purposes.

No Derivative Works. You may not alter, transform, or build upon this work.

- For any reuse or distribution, you must make clear to others the license terms of this work.

- Any of these conditions can be waived if you get permission from the copyright holder.

Your fair use and other rights are in no way affected by the above.

This is a human-readable summary of the Leqal Code (the full license).

\section{Disclaimer 만}

For the full text of this licence, please go to: http://creativecommons.org/licenses/by-nc-nd/2.5/ 
1

2

3

4

5

6

7

Relational Efficacy Beliefs in Physical Activity Classes: A Test of the Tripartite Model

8

SECOND REVISION

9

10

11

12

13

14

15

16

17

18

19

20 Submitted: September $15^{\text {th }}, 2011$

21 Revision submitted: January $12^{\text {th }}, 2012$

22 Second revision submitted: XXXXXX, 2012

23 


\section{Abstract}

This study explored the predictive relationships between students' $\left(N=516, M_{\text {age }}=18.48\right.$,

$3 S D=3.52)$ tripartite efficacy beliefs and key outcomes in undergraduate physical activity classes.

4 Students reported their relational efficacy perceptions (i.e., other-efficacy and relation-inferred

5 self-efficacy, or RISE) with respect to their instructor before a class, and instruments measuring

6 self-efficacy, enjoyment, and effort were administered separately following the class. The

7 following week, an independent observer assessed student achievement. Latent variable path

8 analyses that accounted for nesting within classes revealed (a) that students were more confident

9 in their own ability when they reported favorable other-efficacy and RISE appraisals, (b) a

10 number of direct and indirect pathways through which other-efficacy and RISE predicted

11 adaptive in-class outcomes, and (c) that self-efficacy directly predicted enjoyment and effort, and

12 indirectly predicted achievement. Although previous studies have examined isolated aspects

13 within the tripartite framework, this represents the first investigation to test the full range of direct

14 and indirect pathways associated with the entire model.

18 Key words: other-efficacy, relation-inferred self-efficacy, RISE, self-efficacy, tripartite efficacy 

Self-efficacy represents an individual's belief in his or her capabilities to produce a given

3 course of action (Bandura, 1977), and research spanning five decades has documented the wideranging implications of this social cognition for shaping human functioning (see Beauchamp, Jackson, \& Morton, in press). In sport and exercise contexts, self-efficacy research is well established (see Feltz, Short, \& Sullivan, 2008), and various pathways have been identified through which self-efficacy beliefs promote desirable outcomes, including elevated effort (e.g.,

8 Hutchinson, Sherman, Martinovic, \& Tenenbaum, 2008), the setting of more challenging 9 personal goals (e.g., Boyce \& Bingham, 1997), and optimal performance (e.g., Feltz, Chow, \& Hepler, 2008). Beyond mapping out the correlates of self-efficacy, researchers have also expanded their focus in order to explore the additional efficacy beliefs that develop alongside and complement self-efficacy within interdependent settings (Bandura, 2000; Lent \& Lopez, 2002). In their 'tripartite conceptualization' of efficacy beliefs in close interactions, Lent and

14 Lopez (2002) posited that individuals’ confidence in their own ability to perform in a given context (i.e., self-efficacy) exists alongside their confidence in the capabilities of important others. In sport or exercise classes for instance, alongside class members' confidence in their own ability, they also develop a degree of confidence in their instructor's ability to perform the

18 various tasks associated with his/her role (i.e., other-efficacy). The third construct within the tripartite efficacy framework, termed relation-inferred self-efficacy (RISE), represents a person’s estimation of another person's thoughts. As such, RISE is conceptualized as a metaperception

21 (Kenny \& Acitelli, 2001) involving one’s appraisals about how confident the other person is in one’s own ability (e.g., person A’s estimation of person B's confidence in person A's ability).

23 For instance, in physical activity classes, class members may develop RISE inferences in terms of their estimation of their instructor's confidence in them.

In the same way that self-efficacy operates in independent settings (Bandura, 1997), Lent and Lopez (2002) proposed that a high degree of confidence in one's own ability aligns with a 
1 desirable profile of outcomes within close interactions, in the form of engagement, effort,

2 enjoyment, and personal performance. Lent and Lopez also discussed two broad predictive

3 considerations with respect to the relational efficacy constructs in their model (i.e., other-efficacy,

4 RISE). First, they theorized that other-efficacy and RISE may serve as important cognitive

5 mechanisms within interpersonal contexts that promote individuals' self-efficacy beliefs. To

6 illustrate using the previous example, class members may report greater confidence in their own

7 capabilities when (a) they are highly confident in their instructor's ability (other-efficacy), and/or

8 (b) they believe that their instructor rates their capabilities favorably (RISE).

Second, as well as outlining these inter-relationships between the tripartite constructs,

10 Lent and Lopez (2002) theorized that other-efficacy and RISE may also directly predict various

11 adaptive outcomes in their own right (e.g., effort, enjoyment, performance). When an individual

12 is highly confident in the 'other's' capabilities (other-efficacy) for instance, this engenders a

13 sense of trust and commitment on the part of the perceiver, as well as instilling effort and

14 perseverance in the various activities one performs alongside/under the 'other'. For individuals

15 in instructional settings, goal attainment is highly dependent upon effective guidance from one’s

16 instructor, and as a result the belief that one is being taught by a highly capable individual may

17 therefore directly bolster one's enjoyment and effort in that class. Similarly, with respect to

18 RISE, when individuals believe that their capabilities are viewed favorably by their instructor,

19 this may foster a sense that they are appreciated and supported by that person, and help to

20 reinforce their actions in that domain (Lent \& Lopez, 2002). Lent and Lopez postulated that

21 these effects for RISE may be most pronounced for those in positions of low status/high

22 dependence within close interactions. Therefore, individuals who believe that their instructor is

23 highly confident in their ability (i.e., high RISE), whilst also occupying a dependent role in

24 relation to that person, may report high levels of effort, as well as a desirable pattern of affective

25 responses (e.g., enjoyment). 
An emerging series of investigations has provided support for fundamental aspects of

2 Lent and Lopez's (2002) model within athletic and exercise-based interactions. First, interview

3 and self-report data have provided some support for the notion that individuals' other-efficacy

4 and RISE beliefs may indeed predict their confidence in their own ability, within coach-athlete

5 (e.g., Jackson, Knapp, \& Beauchamp, 2009) and athlete-athlete (e.g., Jackson, Beauchamp, \&

6 Knapp, 2007) exchanges. In addition, physical activity studies with cardiac rehabilitation

7 patients (Bray \& Cowan, 2004) and fitness class attendees (Bray, Gyurcsik, Culos-Reed,

8 Dawson, \& Martin, 2001) have indicated that a high degree of confidence in one's

9 consultant/instructor may account for improvements in one’s own self-efficacy beliefs. Existing

10 work has also shown coaches’ and athletes’ tripartite efficacy beliefs to be independently and

11 positively associated with a range of affective (e.g., positive affect), relational (e.g., relationship

12 commitment, conflict), and behavioral (e.g., task performance) variables (e.g., Dunlop, Beatty, \&

13 Beauchamp, 2011; Jackson \& Beauchamp, 2010; Jackson, Grove, \& Beauchamp, 2010; Jackson,

14 Gucciardi, \& Dimmock, 2011). In sum, existing tripartite studies have documented how other-

15 efficacy and RISE may predict self-efficacy beliefs, as well as separately identifying how each

16 efficacy construct aligns with a range of interpersonal outcomes in one-on-one sporting dyads.

17 Nonetheless, important tenets within Lent and Lopez's (2002) model have yet to be

18 addressed in the tripartite efficacy literature. Most notably, there is an absence of tripartite

19 research that has sought to simultaneously model the inter-relationships between the three

20 efficacy constructs, whilst concurrently considering direct and indirect predictive effects for self-

21 efficacy, other-efficacy, and RISE in relation to important outcomes. The estimation of direct

22 and indirect effects is a substantive extension to the tripartite literature, and a number of authors

23 have recently stressed the importance of specifying structural models that provide insight into

24 intermediary or explanatory variables (e.g., Bullock, Green, \& Ha, 2010). Specifically,

25 identifying the direct and indirect pathways associated with the tripartite constructs presents an

26 opportunity for theory advancement, via improving our understanding of the mechanisms through 
1 which self-efficacy, other-efficacy, and RISE beliefs promote desirable outcomes. In addition,

2 researchers have so far failed to examine the predictive utility of the tripartite constructs within

3 extended (rather than one-on-one) social networks, in which a group of individuals receive

4 instruction from (and develop relational efficacy beliefs about) a central figure. We sought to

5 address these limitations in this study, with a sample of undergraduate students who were

6 participating in graded physical activity classes as part of their degree course. Using members of

7 an undergraduate tennis class, we sought to identify the direct and indirect predictive effects that

8 students' tripartite efficacy beliefs demonstrated in relation to their engagement and achievement

9 levels in their class. Importantly, by recruiting physical activity class members from an

10 educational context, we were able to examine self-reported indicators of student engagement

11 (e.g., effort, enjoyment), as well as modeling the effects of self-efficacy, other-efficacy, and RISE

12 in relation to their achievement levels (i.e., their performance on end-of-semester assessments).

13 Physical activity classes provide important opportunities for promoting healthy

14 extracurricular behaviors and lifelong activity patterns (e.g., Gordon-Larsen, McMurray, \&

15 Popkin, 2000). That said, the transition to undergraduate (i.e., college) studies represents an

16 important developmental milestone that is characterized by marked reductions in activity levels

17 along with less favorable attitudes towards physical activity (e.g., Bray \& Born, 2004). Despite

18 the significance of one's physical activity class experiences, and the important activity-related

19 changes among college students, research into the factors that promote enjoyable and engaging

20 collegiate physical activity classes is limited (Keating, Guan, Piñero, \& Bridges, 2005), and to

21 date, no studies have explored the predictive effects of the tripartite efficacy constructs in college

22 physical activity classes. With that in mind, this investigation sought to extend the efficacy

23 literature by exploring the direct and indirect pathways through which students' self-efficacy,

24 other-efficacy, and RISE perceptions predicted their effort, enjoyment, and achievement in

25 undergraduate physical activity classes. 
The hypothesized relations between variables of interest are presented in Figure 1.

2 Guided by existing theoretical proposals (Lent \& Lopez, 2002), we hypothesized a number of

3 predictive relations for other-efficacy and RISE perceptions. First, we forecasted that other-

4 efficacy and RISE would each be directly (and independently) related to levels of effort and

5 enjoyment in physical activity classes (pathways 1-4 in Figure 1). Lent and Lopez (2002)

6 contended that other-efficacy and RISE each possess important motivational and affective

7 properties, and in light of supporting evidence from athlete-coach interactions (e.g., Jackson \&

8 Beauchamp, 2010), we proposed that students would report higher levels of effort and enjoyment

9 when they (a) believed their class instructor was highly skilled in his/her role (other-efficacy),

10 and (b) felt that their class instructor was highly confident in their capabilities as a student

11 (RISE). Lent and Lopez also outlined that both of the relational efficacy constructs in their

12 model may complement the role of self-efficacy in promoting adaptive performance-related

13 outcomes, and empirical evidence derived from interview-based (e.g., Jackson et al., 2009) and

14 experimental (Dunlop et al., 2011) investigations exists to support their assertions. With that in

15 mind, we forecasted that other-efficacy and RISE perceptions would directly predict high levels

16 of achievement (pathways 5 \& 6).

17 We also hypothesized that students' confidence in their own ability would be greater

18 when they were highly confident in their instructor's ability, and when they held favorable

19 estimations of their instructor's confidence in them (pathways $7 \& 8$ ). These predictive

20 relationships between the tripartite constructs are at the heart of Lent and Lopez's (2002)

21 theoretical assertions. Moreover, the positive effect we forecasted for other-efficacy in relation to

22 self-efficacy is supported by existing research in exercise classes (Bray \& Cowan, 2004; Bray et

23 al., 2001), as well as undergraduate educational contexts (Elias \& MacDonald, 2007), whereby

24 psychology students have been shown to report greater confidence in their own ability when they

25 believe strongly in the capabilities of their faculty members. Similarly, with respect to RISE,

26 studies on reflected appraisals have substantiated the notion that students' self-perceptions may 
1 be shaped by their estimations of their teachers' beliefs about them (e.g., Bouchey \& Harter,

2 2005). In addition, investigations drawing from Rosenthal and Jacobson’s (1968) pioneering

3 work on Pygmalion effects have demonstrated that students' perceptions of their ability in

4 physical activity classes may be derived, in part, from the internalization of the expectations that

5 their teacher/instructor holds for them (e.g., Trouilloud, Sarrazin, Martinek, \& Guillet, 2002).

Having outlined the predictors of self-efficacy beliefs, the final aspect of our hypothesized

7 model targeted the variables predicted by students' self-efficacy beliefs. In short, we

8 hypothesized that self-efficacy would predict enhanced achievement in physical activity classes,

9 not only directly but also indirectly via improvements in effort and enjoyment. Physical activity research in high school and college contexts indicates that students' perceptions of their own

11 ability may shape their enjoyment (pathway 9; e.g., Carroll \& Loumidis, 2001) and effort

12 (pathway 10; e.g., Chase, 2001; Taylor \& Lonsdale, 2010) in their classes. In turn, high levels of 13 effort (e.g., Boiché, Sarrazin, Grouzet, Pelletier, \& Chanal, 2008) and enjoyment/satisfaction 14 (e.g., Theodorakis, 1995) have been linked to optimal achievement in physical activity class settings (pathways $11 \& 12$ ). Therefore, with respect to the indirect relations between selfefficacy and achievement, we predicted that students who were highly confident in their own

17 ability would report greater effort and enjoyment, and that these favorable effects would

18 subsequently contribute to enhanced achievement levels. Effort and enjoyment represent two important explanatory (i.e., mediator) variables in the self-efficacy - achievement relationship; however, self-efficacy theory (Bandura, 1997) and research has shown that individuals’

21 confidence in their own ability also serves as a direct predictor of task execution in physical 22 activity-based instructional contexts (e.g., Lodewyk, Gammage, \& Sullivan, 2009). Our final 23 hypothesized pathway, that self-efficacy perceptions would directly predict higher scores on end24 of-semester assessment (i.e., achievement, pathway 13), was grounded in this literature. In 25 summary, in this study we sought to provide a comprehensive assessment of Lent and Lopez's 26 (2002) tripartite efficacy framework, by simultaneously modeling the relationships between the 
1 tripartite constructs, as well as the direct and indirect pathways through which each of these

2 efficacy beliefs predict important engagement and behavioral outcomes.

\section{Methods}

\section{Participants}

Data were provided by 516 Australian undergraduate students (male $=254$, female $=249$,

613 did not declare), recruited from compulsory physical activity (i.e., tennis) classes $(G=20)$

7 embedded within a three-year undergraduate Sport Science/Kinesiology program. The mean age

8 of participants was 18.48 years $(S D=3.52)$, and all classes were taught by the same male

9 instructor. During the semester in which data were collected, students participated in one 90-

10 minute tennis class per week, and did not participate in any compulsory physical activity classes

11 other than their tennis sessions.

12 Measures

13 Efficacy beliefs. Tripartite efficacy instruments were created for this study in line with

14 Bandura's (2006) scale construction recommendations. First, a group of students who were 15 enrolled in undergraduate physical activity courses $\left(n=39 ; M_{\text {age }}=18.42, S D=2.17\right)$, but not

16 included in the main sample, were asked to complete an open-ended two-section questionnaire.

17 This stage was designed to provide a conceptual analysis of the primary behavioral, emotional,

18 and self-regulatory tasks that contributed to optimal functioning for students (i.e., for self-

19 efficacy and RISE items) and teachers (i.e., other-efficacy items) in this domain. In the first

20 section of the questionnaire, students were requested to "list the most important things that

21 students have to do in order to achieve the best possible grade in this course”. In order to ensure

22 that a sufficiently challenging range of items emerged, students were encouraged to "reflect upon

23 the things that are really important, but aren’t always easy for you to do”. In section two,

24 students were asked to consider the important tasks and skills required of an effective college

25 physical activity class teacher. Although no instrument exists to measure students' other-efficacy

26 in this context, there is a wealth of evidence regarding teacher-related skills/tasks in the teacher 
1 self-efficacy literature. Teacher behaviors related to instruction, classroom management, and

2 promoting student engagement/motivation are evident in several existing teacher self-efficacy

3 scales (e.g., Dellinger, Bobbett, Oliver, \& Ellett, 2008; Tschannen-Moran \& Woolfolk Hoy,

4 2001), and so in section two we prompted students to consider "the various things your teacher

5 does, which might include the instructions they give you, the way they behave toward you and

6 your class, and their ability to motivate you, among other things”.

To develop items for self-efficacy/RISE we examined open-ended responses from section

8 one for recurring student-related themes. Similarly, common teacher-related factors that were

9 identified in section two formed the basis of our other-efficacy instrument. An initial battery of

1016 self-efficacy/RISE and 15 other-efficacy items was subsequently presented to four

11 experienced self-efficacy/education researchers and five undergraduate students, who were

12 provided with definitions for each tripartite construct and were asked to give qualitative feedback

13 on item representativeness, ambiguity, overlap, understanding, and jargon. Researchers (but not

14 undergraduates) were also asked to provide quantitative ratings regarding the relevance of each

15 item, using a 5-point scale anchored at -2 (very poor) and 2 (very good) (Haynes, Richard, \&

16 Kubany, 1995). Given the limited number of expert reviewers, items were eliminated in

17 instances where mean or median scores fell below 1.0. Following expert and undergraduate

18 feedback, minor wording changes were made to a number of items as a result of qualitative

19 comments. In addition, seven self-efficacy/RISE items with mean or median reviewer scores $<$

201.0 were dropped, and five other-efficacy items were also removed on the same basis. These

21 modifications resulted in a final pool of nine student-related self-efficacy/RISE items and 10

22 teacher-related other-efficacy items.

23 Self-efficacy was operationalized by presenting the list of nine items following the

24 instruction, "please honestly rate your confidence in your own ability at this moment in time

25 to...” Example items included, "learn all the skills you are taught”, “persevere during technically

26 difficult periods", and "be able to effectively teach the skills you learn in this class", and 
1 responses were made on a five-point scale anchored at 1 (no confidence at all) and 5 (complete

2 confidence). For other-efficacy, students were asked to rate their confidence in their teacher's

3 ability at that moment in time on the series of 10 items. Items included, "explain concepts

4 effectively at all times”, “display excellent knowledge of the subject area”, and "give

5 individualized feedback on your progress”, and an identical five-point response format was used.

6 The nine items measuring RISE beliefs were exactly the same as those for self-efficacy; however,

7 the instruction was changed in order to ask students to estimate how confident they thought their

8 teacher was in their ability at that point in time, according to the same five-point response scale.

9 Although Bandura (2006) recommends the use of an 11-point response format for measuring

10 efficacy beliefs, psychometric analyses in physical activity contexts have recently provided

11 compelling empirical support for the condensed five-point format employed in this study (Myers,

12 Feltz, \& Wolfe, 2008; Myers, Wolfe, \& Feltz, 2005).

13 Effort. Students rated their effort relating to their physical activity classes using the five-

14 item effort subscale from the Intrinsic Motivation Inventory (IMI; Ryan, 1982). Using a seven-

15 point response scale anchored at 1 (not at all true) and 7 (very true), participants responded to

16 items that were tailored to the activity they were studying, for instance "I put a lot of effort into

17 my tennis classes" and "I try very hard in my tennis classes". In previous educational physical

18 activity research, measures derived from this instrument have demonstrated acceptable levels of

19 internal consistency (e.g., Taylor \& Lonsdale, 2010) and evidence of unidimensionality (e.g.,

20 McAuley, Duncan, \& Tammen, 1989), as well as favorable correlations with theoretically-related

21 variables (e.g., perceived competence; Goudas \& Biddle, 1994).

Enjoyment. Enjoyment was assessed using a seven-item scale derived from Pekrun and

23 colleagues’ Achievement Emotions Questionnaire - Mathematics (AEQ-M; Pekrun, Goetz, \&

24 Frenzel, 2005). Items in the AEQ-M target one’s perceptions about a given class, and in the

25 present study we simply modified the referent to focus on physical activity rather than

26 mathematics classes (see Goetz, Frenzel, Hall, \& Pekrun, 2008). Three redundant items were 
1 also dropped from the original scale (i.e., "when doing my [subject] homework, I am in a good

2 mood”, "I enjoy doing my [subject] homework so much that I am motivated to do extra

3 assignments”, “Because I look forward to getting a good grade, I study hard for the test”).

4 Exemplar items used for this study included, "I look forward to my tennis class", "I enjoy my

5 tennis class", and "the skills we learn in tennis are so interesting that I really enjoy the class".

6 Responses were scored from 1 (not at all) to 5 (very much). Researchers have previously

7 demonstrated acceptable levels of internal consistency for measures derived from this instrument

8 (e.g., Goetz et al., 2008), and factor analyses have provided support for the structural properties

9 of the AEQ-M (e.g., Goetz, Frenzel, Pekrun, Hall, \& Lüdtke, 2007). Previous studies have also

10 documented evidence of discriminant validity for the AEQ-M (Pekrun et al., 2005), as well as

11 gender-related measurement invariance (Goetz et al., 2008), and support for criterion validity via

12 associations with theoretically-related variables, such as academic self-concept (e.g., Goetz et al.,

13 2008) and achievement (e.g., Goetz, Cronjaeger, Frenzel, Lüdtke, \& Hall, 2010).

Achievement. Physical activity class achievement was measured via end-of-semester assessments. In the penultimate week of the semester, students undertook a series of technical, tactical, and instructional tasks specific to their focal activity (i.e., tennis). In particular, students

17 were required to execute a series of strokes, devise a hypothetical strategy for a single game, and 18 provide instruction/diagnostic feedback to another student on a technical skill of the instructor's 19 choosing. Student performance was rated on these tasks by a single expert observer who was unaware of the specific purposes of the investigation and had over 15 years experience assessing

21 student achievement in undergraduate tennis classes. An aggregate percentage score was

22 calculated for each student following completion of all assessment components.

\section{Procedure}

Upon receipt of ethical approval from the human subjects ethics board at the lead author's institution, three physical activity course coordinators were contacted by email to inform them about the nature of the study and invite them and their students to take part (one coordinator 
1 agreed to participate). Questionnaire completion was scheduled during class time at a point late

2 in the academic semester (i.e., week 11 of 13), in order to ensure that students had sufficient

3 experience upon which to base their responses. All data collection sessions were facilitated by

4 the first author, and students were informed about the nature of the investigation at the start of the

5 pre-arranged class. Prior to questionnaire completion, students were assured in writing that all

6 information that they provided would remain strictly confidential, that they were free to withdraw

7 at any time, and could choose not to answer any question they wished. They were also made

8 aware (verbally and in writing) that their responses would in no way impact their course grade,

9 and that their instructor and classmates would not be made aware of their responses at any stage.

10 No incentives were offered for participation; students were informed that their

11 participation was entirely voluntary, and were notified that if they did not wish to participate they

12 were able to view the questionnaire and ask any questions they wished about the investigation.

13 Students were also asked to declare whether they had participated in any organized tennis

14 tournaments or were receiving formalized tennis coaching outside their compulsory tennis classes

15 during the semester, and were informed that anyone who had done so would be ineligible to

16 participate in the investigation. In total, 563 students were notified about the study, 537 agreed

17 and were eligible to participate (95.4\% participation), and 516 provided complete data across all

18 time points (96.1\% retention). After students who agreed to participate had provided their

19 informed consent, they were instructed to complete questionnaires privately and individually. In

20 light of the overlap between self-efficacy and RISE items, we sought to avoid any

21 methodological inflation of the relationship between these variables. To achieve this,

22 respondents were asked to rate their other-efficacy and RISE perceptions at the beginning of their

23 physical activity class, and then completed self-efficacy, effort, and enjoyment measures

24 approximately 90 minutes later at the close of the class. The following week (i.e., the

25 penultimate week of the semester), all students undertook their end-of-semester practical

26 assessment, and percentage grades were emailed by the course coordinator to the lead author. 


\section{Data Analysis}

Missing data comprised $0.4 \%$ of all cases, and were handled under the assumption that the data were missing at random (Collins, Schafer, \& Kam, 2001). A correction for nonindependence of the observations based on students being nested within classes (Asparouhov \& Muthén, 2006) was implemented in Mplus 6 (Muthén \& Muthén, 1998-2010). A latent variable path model was imposed on the data consistent with Figure 1, and we modeled all observed data (with the exception of achievement) as ordinal, using weighted least squares mean- and varianceadjusted (WLSMV) estimation. Nine items were specified as indicators for latent selfefficacy/RISE variables, and 10 items (i.e., indicators) were used to represent other-efficacy. Effort and enjoyment were represented by five and seven indicators, respectively, and student achievement was modeled as a single-item observed variable. Construct reliability was measured with coefficient $H$ (Hancock \& Mueller, 2001). We considered a number of indices to assess model fit for our latent variable path model, namely the $\chi^{2}$ goodness-of-fit index, comparative fit index (CFI), Tucker-Lewis index (TLI), and root mean square error of approximation (RMSEA). Established criteria were used to assess overall model fit, CFI and TLI $\geq .95$, and RMSEA $\leq .08$ (Hu \& Bentler, 1999; Marsh, Hau, \& Wen, 2004). We modeled the direct as well as indirect pathways between our latent (i.e., efficacy perceptions, enjoyment, effort) and observed (i.e., achievement) variables, as well as computing the amount of variance explained in each of our endogenous variables. Computational details for direct, indirect, and total effects can be found in MacKinnon (2008).

\section{Results}

\section{Descriptives, Correlations, and Fit Indices}

Descriptive statistics and zero-order correlations are reported in Table 1. Fit indices revealed that the data were a close overall fit for a model that included all indicators (i.e., all items) for self-efficacy, other-efficacy, RISE, enjoyment, and effort, as well as all structural pathways between latent and observed variables, $\chi^{2}(751)=993.15, p<.001$, CFI $=.98$, TLI $=$ 
1.98 , and RMSEA $=.025$ (90\% confidence interval .021 - .029). Standardized factor loadings

2 were in the range $.54-.75, .75-.92$, and $.74-.79$ for self-efficacy, other-efficacy, and RISE,

3 respectively, and .61 - .86 for effort, and .70 - .92 for enjoyment.

\section{Main Analyses}

Direct effects. Path analyses revealed a number of significant direct effects between

6 study variables (see Figure 2). Students reported greater confidence in their own ability (i.e.,

7 self-efficacy) when they believed strongly in their instructor's capabilities (i.e., other-efficacy)

8 and when they estimated that their instructor was highly confident in them (i.e., RISE), and

9 collectively, other-efficacy and RISE percepts accounted for a combined 69\% of the total

10 variance in self-efficacy scores. Analysis of the association between other-efficacy and RISE

11 also demonstrated that students' confidence in their instructor and their estimation of their

12 instructor's confidence in them were positively related. RISE beliefs did not directly predict

13 ratings of in-class effort or enjoyment; however, favorable other-efficacy and self-efficacy

14 perceptions were each independently predictive of greater enjoyment and effort. In combination,

15 the tripartite efficacy constructs explained $63 \%$ of the variance in enjoyment and $60 \%$ of the

16 variance in effort scores. In terms of the variables predicting achievement, other-efficacy and

17 enjoyment emerged as significant contributors to end-of-semester assessment scores. No effects

18 were observed for effort or self-efficacy, and the positive direct effect that was observed for RISE

19 on achievement did not reach significance. Overall, these predictors cumulatively accounted for

$2031 \%$ of the variance in achievement scores, and analyses revealed significant effects for 8 of the

2113 hypothesized direct pathways outlined in the a priori model.

Indirect effects. Alongside these direct relationships, we also observed a number of

23 indirect effects. A significant total indirect effect emerged for other-efficacy (but not self-

24 efficacy or RISE) in relation to students’ physical activity class achievement (Table 2). As a

25 proportion of the total effect for each of the tripartite constructs, total indirect estimates

26 demonstrated that mediating (i.e., indirect) pathways accounted for $36.6 \%$ of the relationship 
1 between self-efficacy and achievement, $45.9 \%$ of the relationship between other-efficacy and

2 achievement, and $24.1 \%$ of the relationship between RISE and achievement. Subsequent analysis

3 of specific indirect effects for self-efficacy revealed that students' confidence in their own ability

4 predicted higher achievement scores via more adaptive enjoyment (but not effort) perceptions

$5 \quad$ (i.e., self-efficacy $\rightarrow$ enjoyment $\rightarrow$ achievement). Analysis of specific effects also documented

6 the indirect sequences through which other-efficacy and in-class outcomes were linked. Most

7 notably, a high level of confidence in one's instructor predicted higher achievement scores, first

8 through increases in enjoyment (i.e., other-efficacy $\rightarrow$ enjoyment $\rightarrow$ achievement), and second,

9 via an additional (and more intricate) pathway that also included self-efficacy (i.e., other-efficacy

$10 \rightarrow$ self-efficacy $\rightarrow$ enjoyment $\rightarrow$ achievement). Aside from achievement-related effects, a high

11 level of confidence in one's instructor was also shown to indirectly predict increased effort (i.e.,

12 other-efficacy $\rightarrow$ self-efficacy $\rightarrow$ effort) and enjoyment (i.e., other-efficacy $\rightarrow$ self-efficacy $\rightarrow$

13 enjoyment), by bolstering students' confidence in their own capabilities. Three noteworthy

14 indirect effects emerged for students' appraisals of their instructor's confidence in their ability.

15 In particular, not only did RISE estimations predict enhanced achievement indirectly via

16 strengthened self-efficacy and enjoyment perceptions (i.e., RISE $\rightarrow$ self-efficacy $\rightarrow$ enjoyment

$17 \rightarrow$ achievement), they also underpinned improvements in effort (i.e., RISE $\rightarrow$ self-efficacy $\rightarrow$

18 effort) and enjoyment (i.e., RISE $\rightarrow$ self-efficacy $\rightarrow$ enjoyment) via a heightened level of

19 confidence in one’s own ability.

\section{Discussion}

Existing tripartite efficacy research in dyadic settings has provided insight into the social

22 cognitive factors that underpin relationship processes (e.g., Jackson et al., 2010). To date though,

23 no single study has attempted to model the predictive pathways that exist between the tripartite

24 constructs, whilst also estimating the outcomes that are directly and/or indirectly associated with

25 self-efficacy, other-efficacy, and RISE. To address this limitation, we examined students'

26 beliefs about their instructor's capabilities (i.e., other-efficacy) and cognitions (i.e., RISE) in 
1 relation to their confidence in their own ability (i.e., self-efficacy), whilst also identifying the

2 numerous direct and indirect (i.e., mediating) pathways between the tripartite constructs and

3 students' effort, enjoyment, and achievement in a collegiate physical activity class setting. The

4 results of this study revealed a series of noteworthy findings. First, students' relational efficacy

5 perceptions about their instructors (i.e., other-efficacy, RISE) appeared to play a pivotal role in

6 predicting their confidence in their own ability. Second, other-efficacy and RISE also exhibited

7 multiple direct and indirect predictive pathways with respect to effort, enjoyment, and

8 achievement. Finally, we also observed positive effects for students' self-efficacy perceptions in

9 relation to physical activity class outcomes.

Lent and Lopez (2002) asserted that strong other-efficacy and RISE perceptions bolster

11 individuals' confidence in their own ability, whilst also promoting desirable outcomes in their

12 own right. Although these effects have been explored previously in isolation, the model we

13 examined in this investigation enabled us to consider both of these potential functions

14 simultaneously. First, students reported greater confidence in their own ability when they had the

15 sense that their physical activity class instructor was highly capable (i.e., other-efficacy), and

16 when they estimated that their instructor viewed them as highly competent (i.e., RISE). In

17 support, existing research has illustrated that athletes, coaches, and exercisers report greater

18 confidence in their own ability when they are highly confident in those with whom they are

19 highly interdependent (i.e., their coach, athlete, trainer), or when they estimate that the other

20 person is confident in them (e.g., Bray \& Cowan, 2004; Jackson et al., 2009). We recognize that

21 our study design precludes any inferences regarding causality; however, these inter-relationships

22 indicate that other-efficacy and RISE may supplement Bandura’s (1997) primary sources of

23 personal efficacy by exerting salient (self-) efficacy-enhancing effects within interpersonal

24 contexts.

Not only did other-efficacy and RISE exhibit positive effects in relation to self-efficacy, 
1 enjoyment, effort, and achievement levels. Lent and Lopez (2002) theorized that a high level of

2 confidence in another's capabilities drives inclusionary orientations when working

3 alongside/under that individual, which in turn stimulate improvements in key affective (e.g.,

4 enjoyment) and motivational (e.g., effortful activity) markers in that domain. In line with our

5 hypotheses and with existing tripartite efficacy research (e.g., Jackson \& Beauchamp, 2010),

6 students' other-efficacy beliefs in this investigation displayed positive direct pathways in relation

7 to enjoyment and effort. In addition, we also observed a significant direct pathway between

8 other-efficacy and achievement, indicating that students' confidence in their instructor was

9 important in its own right in terms of supporting their attainment levels in their physical activity

10 class (cf. Dunlop et al., 2011). Alongside these direct effects, our analyses of indirect pathways

11 illustrated the potential mechanisms through which students' other-efficacy judgments exhibited

12 downstream effects on distal outcomes. We observed that a high level of confidence in one's

13 instructor's capabilities was associated with enhanced achievement via (a) a predictive chain that

14 included improvements in physical activity class enjoyment, and (b) an additional pathway in

15 which other-efficacy predicted higher self-efficacy, which was in turn related to greater

16 enjoyment and achievement. RISE beliefs did not directly contribute to increments in students'

17 enjoyment or effort. That said, favorable estimations of one's instructor's confidence in one's

18 ability did predict both of these outcomes indirectly through improvements in self-efficacy

19 beliefs. Moreover, although the direct pathway between RISE and achievement did not reach

20 significance, RISE inferences did account for elevated achievement scores via an indirect

21 pathway through self-efficacy and enjoyment. Taken together, the direct and indirect

22 relationships we detected for other-efficacy and RISE indicated that these relational constructs

23 not only predict students' confidence in their own ability, but also make a unique prospective

24 contribution to behavioral outcomes, both directly (in the case of other-efficacy) and indirectly

25 via important cognitive and affective variables. 
As hypothesized, the findings linking self-efficacy with enjoyment and effort not only

2 support key theoretical tenets (Bandura, 1997; Lent \& Lopez, 2002), they also corroborate the

3 adaptive correlates of self-efficacy perceptions found in physical activity class settings (Carroll \&

4 Loumidis, 2001; Chase, 2001), as well as existing tripartite efficacy research within dyadic

5 interactions (Jackson et al., 2009). Embarking on one’s collegiate studies consistently coincides

6 with reductions in activity levels (e.g., Keating et al., 2005), as well as indices of physical and

7 psychosocial health (e.g., Bray \& Kwan, 2006), and it is also recognized that positive experiences

8 of physical activity within educational environments may translate into more favorable

9 perceptions about, and levels of, leisure-time exercise (e.g., Hagger, Chatzisarantis, Barkoukis,

10 Wang, \& Baranowski, 2005). Although we did not assess any extracurricular variables in this

11 investigation, an interesting next step from an epidemiological perspective would be to examine

12 whether greater enjoyment and/or effort in undergraduate physical activity classes may mediate a

13 trans-contextual relationship between tripartite perceptions in educational settings and leisure-

14 time physical activity engagement.

In terms of other direct self-efficacy effects, we did not observe a significant relationship

16 between students' confidence in their ability and their achievement levels. Analyses of indirect

17 pathways did, however, demonstrate that self-efficacy was significantly associated with

18 achievement via increases in enjoyment. Although the emergence of this predictive sequence

19 (i.e., self-efficacy $\rightarrow$ enjoyment $\rightarrow$ achievement) is novel in this context, several contemporary

20 sources support our finding that optimal achievement occurs when individuals experience high

21 levels of enjoyment in a given domain. For instance, recent empirical evidence indicates that a

22 positive affective tone (i.e., enjoyment, happiness) may underpin improved grades in educational

23 activities (e.g., Ruthig et al., 2008), supporting Pekrun’s (e.g., Pekrun, Goetz, Titz, \& Perry,

24 2002) control-value notion that enjoyment acts an 'activating' emotion which stimulates

25 productivity and engagement (e.g., concentration, attainment). Bearing in mind that achievement

26 in this study was measured via observer ratings of instructional and technical ability, it is also 
1 important to note that individuals displaying high levels of enjoyment have been shown to

2 consistently experience better social interactions and receive more favorable evaluations from

3 others (see Lyubomirsky, King, \& Diener, 2005).

Prior to outlining general directions for further study it is important to note that despite detecting several hypothesized effects our analyses failed to provide evidence for two key aspects of our a priori model. First, contrary to our hypotheses, RISE appraisals were not directly related to enjoyment, effort, or achievement; rather, they displayed only a single (but strong) predictive relationship with respect to self-efficacy perceptions. This solitary effect implies that RISE may have served as an efficacy-enhancing or -reducing construct for these students, and did not align with other adaptive outcomes in its own right. Lent and Lopez (2002) articulated that the consequences of RISE beliefs may be moderated by the characteristics of the 'target' individual (e.g., his/her credibility and expertise), as well as the nature of the interaction in question (e.g., disparities between the relative authority of interactants). The high scores we observed for students' other-efficacy perceptions indicated that these physical activity instructors were viewed as highly credible, and as well as being an important authority figure, educational instructors are also a crucial source of competence information for students (Bandura, 1993). Given that instructors and teachers hold such a potent influence in terms of gauging and nurturing students’ academic capabilities, favorable RISE perceptions (about a teacher) may act primarily as a form of diagnostic information that serves simply to bolster one’s belief in one’s own ability (which then, in turn, predicts additional desirable outcomes). It would be interesting to test for divergent effects when examining RISE perceptions within other interactions (e.g., student-student, or athlete-athlete partnerships), where one’s partner does not hold an authority position and may represent a somewhat less credible source of competence-based information. In these exchanges, 4 believing that an 'equal' is highly confident in one's capabilities may do less to substantively 5 influence one's confidence in one's own ability (in comparison to RISE beliefs focused on a 
1 instructor), but may make a relatively greater contribution to one’s affective state given the

2 greater interdependence that exists between partners.

It was also noteworthy that effort did not predict performance on end-of-semester assessment when controlling for the effects of enjoyment and self-efficacy. The nonsignificant coefficient for effort in this instance may have been due to the type of assessment undertaken by the students. In particular, given that a positive affective tone promotes favorable interpersonal

7 evaluations from others (Lyubomirsky et al., 2005), the assessment modality may have

8 emphasized enjoyment as a contributor to achievement ratings (at the expense of effort). The assessment also consisted, in part, of an instructional (one-on-one coaching) activity within which effective performance may have relied upon the extent to which students were happy and

11 enthusiastic, rather than on their sustained (i.e., semester-long) level of effort.

The present findings underscore the important role of self-efficacy, other-efficacy, and

13 RISE in shaping key physical activity-related outcomes, and also highlight the considerable scope

14 for future tripartite efficacy research that explores achievement and engagement in group physical activity and educational contexts. With respect to design issues, it is important to recognize that we recruited a cohort of students from an educational setting, and future work is required that

17 examines the relative effects of other-efficacy and RISE beliefs in other contexts (e.g.,

18 recreational groups), and with respect to additional outcome variables (e.g., leisure-time physical

19 activity). As well as broadening the scope of future research in this area, observational and

20 experimental studies could be utilized to provide more robust insight into tripartite causal effects

21 (see Imai, Keele, Tingley, \& Yamamoto, 2011). Imai and colleagues (2011) described how the

22 systematic manipulation of independent and mediating variables can be used in experimental

23 scenarios in order to identify causal pathways, and outlined appropriate design/computational

24 approaches in cases when the mediator (e.g., effort, enjoyment) can and cannot be accurately

25 modified by researchers. Alternatively, observational approaches for approximating causality

26 using instrumental variables might also be employed in this context (see Didelez, Meng, \& 
1 Sheehan, 2010). Instrumental variable designs allow researchers to circumvent concerns that are

2 traditionally associated with observational studies (e.g., unmeasured variables, directionality of

3 pathways), by discounting the influence of unmeasured confounds on the relations between a

4 given independent and outcome variable (for a technical overview and illustration, see Didelez et

5 al., 2010). In future, this approach would enable investigators to more confidently test the

6 proposed causal relations between efficacy beliefs, intermediary variables (e.g., enjoyment), and

7 behavioral outcomes (e.g., achievement).

8 Future research would also be worthwhile that considers potential moderators of these

9 effects. For example, it is possible that other-efficacy and RISE may support self-efficacy and

10 physical activity class engagement only in cases where subject matter is personally valued by the

11 student (Bandura, 1997). In instances when students place little import in an activity (e.g., "I just

12 don’t see the point of physical activity classes”), adaptive relational cognitions about one's

13 instructor (i.e., other-efficacy, RISE) may be insufficient to promote optimal affective and

14 behavioral outcomes. Similarly, it would be intriguing to explore the predictive effects of other-

15 efficacy and RISE when considering 'target' individuals other than one’s instructor. For

16 example, as we noted when discussing RISE effects, future work that explores individuals'

17 estimations of their classmates' confidence in their ability may provide novel insight into the role

18 of metaperceptions with respect to feelings of acceptance, comfort, and competence in physical

19 activity class environments. Given that self-evaluative concerns and social anxiety are often

20 evoked through such classes (e.g., Gammage, Martin Ginis, \& Hall, 2004), examining RISE in

21 relation to one's classmates may be particularly enlightening in terms of understanding the social

22 cognitive influences on engagement and emotional responses in these settings.

23 Another limitation of our study was the rejection of the null hypothesis for exact fit.

24 Given that the latent variable model was saturated, and in light of the modification indices we

25 observed, it is likely that the misfit was attributable to various facets of the measurement (rather

26 than structural) model. Although the observed modification indices suggested that alterations to 
1 the measurement model may have helped us achieve exact fit, our aim was to focus on exploring

2 structural pathways in this investigation (rather than designing a measurement study), and as a

3 result these changes were not theoretically justifiable. In light of this, along with the known

4 problem of capitalization on chance by making post hoc model modifications due to empirical

5 information alone, we opted to accept our close but inexact fitting model. Future research that

6 explores improvements in the measurement portion of our model is warranted.

Finally, further work is required that considers additional indirect pathways beyond those

8 tested in this study. For instance, Lent and Lopez (2002) contended that favorable tripartite

9 efficacy perceptions account for improvements in one’s perceptions of relationship quality.

10 Several instruments exist that measure students' perceptions about the quality of their exchanges

11 with their teachers/instructors (e.g., Hughes, Cavell, \& Willson, 2001), and it would be

12 interesting to investigate how perceptions of student-instructor interaction quality may mediate

13 the relationship between tripartite efficacy constructs and achievement-related outcomes, and/or

14 contribute to more favorable leisure-time physical activity attitudes and behaviors.

Despite presenting support for selected aspects of Lent and Lopez’s (2002) efficacy

16 framework, existing research has yet to explore the tripartite model in its entirety by testing the

17 range of direct and indirect pathways associated with self-efficacy, other-efficacy, and RISE.

18 Drawing from Lent and Lopez’s (2002) conceptualization, this study demonstrated that

19 individuals' relational efficacy beliefs about their physical activity class instructor (i.e., other-

20 efficacy and RISE) predicted enhanced confidence in their own ability, and also prospectively

21 accounted for direct and/or indirect increases in enjoyment, effort, and achievement. This study

22 not only provides the first comprehensive examination of the tripartite model in close

23 interactions, these findings also support the expansion of tripartite efficacy research in physical

24 activity contexts. 


\section{References}

Asparouhov, T., \& Muthén, B. O. (2006). Multilevel modeling of complex survey data. In Proceedings of the Joint Statistical Meeting, USA, American Statistical Association Section on Survey Research Methods (pp. 2718-2726), Seattle, WA.

Bandura, A. (1977). Self-efficacy: Toward a unifying theory of behavioral change. Psychological Review, 84, 191-215. doi: 10.1037/0033-295X.84.2.191

Bandura, A. (1993). Perceived self-efficacy and cognitive development and functioning. Educational Psychologist, 28, 117-148. doi: 10.1207/s15326985ep2802_3

Bandura, A. (1997). Self-efficacy: The exercise of control. New York: Freeman and Company. doi: 10.1177/0957154X9400501708

Bandura, A. (2000). Exercise of human agency through collective efficacy. Current Directions in Psychological Science. 9, 75-78. doi: 10.1111/1467-8721.00064

Bandura, A. (2006). Guide for constructing self-efficacy scales. In F. Pajares \& T. Urdan (Eds.), Self-efficacy beliefs of adolescents (pp. 307-337). Greenwich, CT: Information Age Publishing.

Beauchamp, M. R., Jackson, B., \& Morton, K. (in press). Efficacy beliefs and human performance: From independent action to interpersonal functioning. In S. Murphy (Ed.), The Oxford handbook of sport and performance psychology. New York: Oxford University Press.

Boiché, J. C. S, Sarrazin, P. G., Grouzet, F. M. E., Pelletier, L. G., \& Chanal, J. P. (2008) Students’ motivational profiles and achievement outcomes in physical education: A selfdetermination perspective. Journal of Educational Psychology, 100, 688-701. doi: 10.1037/0022-0663.100.3.688

Bouchey, H. A., \& Harter, S. (2005). Reflected appraisals, academic self-perceptions, and math / science performance during early adolescence. Journal of Educational Psychology, 97, 673-686. doi: 10.1037/0022-0663.97.4.673 
1 Boyce, B. A., \& Bingham, S. M. (1997). The effects of self-efficacy and goal setting on bowling performance. Journal of Teaching in Physical Education, 16, 312-323.

Bray, S. R., \& Born, H.A. (2004). Transition to university and vigorous physical activity: Implications for health and psychological well-being. Journal of American College Health, 52, 181-188. doi: 10.3200/JACH.52.4.181-188

Bray, S. R. \& Cowan, H. (2004). Proxy efficacy: Implications for self-efficacy and exercise intentions in cardiac rehabilitation. Rehabilitation Psychology, 49, 71-75. doi: 10.1037/0090-5550.49.1.71

Bray, S. R., Gyurcsik, N. C., Culos-Reed, S. N., Dawson, K. A., \& Martin, K. A. (2001). An exploratory investigation of the relationship between proxy efficacy, self-efficacy and exercise attendance. Journal of Health Psychology, 6, 425-434. doi: 10.1177/135910 530100600405

Bray, S. R., \& Kwan, M. Y. W. (2006). Physical activity is associated with better health and psychological well-being during transition to university life. Journal of American College Health, 55, 77-82. doi: 10.3200/JACH.55.2.77-82

Bullock, J. G., Green, D. P., \& Ha, S. E. (2010). Yes, but what's the mechanism? (Don’t expect an easy answer). Journal of Personality and Social Psychology, 98, 550-558. doi: 10.1037/a0018933

Carroll, B., \& Loumidis, J. (2001). Children’s perceived competence and enjoyment in physical education and physical activity outside school. European Physical Education Review, 7, 24-43. doi: 10.1177/1356336X010071005

Chase, M. A. (2001). Children’s self-efficacy, motivational intentions, and attributions in physical education and sport. Research Quarterly for Exercise and Sport, 72, 47-54.

Collins, L. M., Schafer, J. L., \& Kam, C. H. (2001). A comparison of inclusive and restrictive strategies in modern missing data procedures. Psychological Methods, 6, 330-351. doi: 10.1037/1082-989X.6.4.330 
1 Dellinger, A. B., Bobbett, J. J., Olivier, D. F., \& Ellett, C. D. (2008). Measuring teachers' selfefficacy: Development and use of the TEBS-Self. Teaching and Teacher Education, 24, 751-766. doi: 10.1016/j.tate.2007.02.010

Didelez, V., Meng, S., \& Sheehan, N. U. (2010). Assumptions of IV methods for observational epidemiology. Statistical Science, 25, 22-40. doi: 10.1214/09-STS316

Dunlop, W. L., Beatty, D. J., \& Beauchamp, M. R. (2011). Examining the effect of other-efficacy and self-efficacy on personal performance. Journal of Sport \& Exercise Psychology, 33, 586-593.

Elias, S. M., \& MacDonald, S. (2007). Using past performance, proxy efficacy, and academic self-efficacy to predict college performance. Journal of Applied Social Psychology, 37, 2518-2531. doi: 10.1111/j.1559-1816.2007.00268.x

Feltz, D., L., Chow, G. M., \& Hepler, T. L. (2008). Path analysis of self-efficacy and diving performance revisited. Journal of Sport \& Exercise Psychology, 30, 401-411.

Feltz, D. L., Short, S. E., \& Sullivan P. J. (2008). Self-efficacy in sport. Champaign, IL: Human Kinetics.

Gammage, K. L., Martin Ginis, K. A., \& Hall, C. R. (2004). Self-presentational efficacy: Its influence on social anxiety in an exercise context. Journal of Sport \& Exercise Psychology, 26, 179-190.

Goetz, T., Cronjaeger, H., Frenzel, A. C., Lüdtke, O., \& Hall, N. C. (2010). Academic selfconcept and emotion relations: Domain specificity and age effects. Contemporary Educational Psychology, 35, 44-58. doi: 10.1016/j.cedpsych.2009.10.001

Goetz, T., Frenzel, A. C., Hall, N. C., \& Pekrun, R. (2008). Antecedents of academic emotions: Testing the internal/external frame of referencemodel for academic enjoyment. Contemporary Educational Psychology, 33, 9-33. doi: 10.1016/j.cedpsych.2006.12.002 
1 Goetz, T., Frenzel, A. C., Pekrun, R., Hall, N. C., \& Lüdtke, O. (2007). Between- and withindomain relations of students’ academic emotions. Journal of Educational Psychology, 99, 715-733. doi: 10.1037/0022-0663.99.4.715

Gordon-Larsen, P., McMurray, R. G., \& Popkin, B. M. (2000). Determinants of adolescent physical activity and inactivity patterns. Pediatrics, 105, 1-8. doi: 10.1542/peds.105.6.e83

Goudas, M., \& Biddle, S. J. H. (1994). Perceived motivational climate and intrinsic motivation in 250. doi: 10.1007/BF03172783

Hagger, M. S., Chatzisarantis, N. L. D., Barkoukis, V., Wang, C. K. J., \& Baranowski, J. (2005). Perceived autonomy support in physical education and leisure-time physical activity: A cross-cultural evaluation of the trans-contextual model. Journal of Educational Psychology, 97, 376-390. doi: 10.1037/0022-0663.97.3.376

Hancock, G. R., \& Mueller, R. O. (2001). Rethinking construct reliability within latent variable systems. In R. Cudeck, S. H. C. du Toit, \& D. Sörbom (Eds.), Structural equation modeling: Past and present. A festschrift in honor of Karl G. Jöreskog (pp. 195-261). Chicago: Scientific Software International, Inc.

Haynes, S. N., Richard, D. C. S., \& Kubany, E. S. (1995). Content validity in psychological assessment: A functional approach to concepts and methods. Psychological Assessment, 7, 238-247. doi: 10.1037//1040-3590.7.3.238

Hu, L., \& Bentler, P. M. (1999). Cutoff criteria for fit indexes in covariance structure analysis: Conventional criteria versus new alternatives. Structural Equation Modeling, 6, 1-55. doi: $10.1080 / 10705519909540118$

Hughes, J. N., Cavell, T., A., \& Willson, V. (2001). Further support for the developmental significance of the quality of the teacher-student relationship. Journal of School Psychology, 39, 289-302. doi: 10.1016/S0022-4405(01)00074-7 
1 Hutchinson, J. C., Sherman, T., Martinovic, N., \& Tenenbaum, G. (2008). The effect of manipulated self-efficacy on perceived and sustained effort. Journal of Applied Sport Psychology, 20, 457-472. doi: 10.1080/10413200802351151

Imai, K., Keele, L., Tingley, D., \& Yamamoto, T. (2011). Unpacking the black box of causality: Learning about causal mechanisms from experimental and observational studies. American Political Science Review, 105, 765-789. doi: 10.1017/S0003055411000414

Jackson, B., Beauchamp, M. R., \& Knapp, P. (2007). Relational efficacy beliefs in athlete dyads:

Jackson, B., \& Beauchamp, M. R. (2010). Efficacy beliefs in athlete-coach dyads: Prospective relationships using actor-partner interdependence models. Applied Psychology: An International Review, 59, 220-242. doi: 10.1111/j.1464-0597.2009.00388.x An investigation using actor-partner interdependence models. Journal of Sport \& Exercise Psychology, 29, 170-189.

Jackson, B., Grove, J. R., \& Beauchamp, M. R. (2010). Relational efficacy beliefs and relationship quality within coach-athlete dyads. Journal of Social and Personal Relationships, 27, 1035-1050. doi: 10.1177/0265407510378123

Jackson, B., Gucciardi, D. F., \& Dimmock, J. A. (2011). Tripartite efficacy profiles: A cluster analytic investigation of athletes’ perceptions of their relationship with their coach. Journal of Sport \& Exercise Psychology, 33, 394-415.

Jackson, B., Knapp, P., \& Beauchamp, M. R. (2009). The coach-athlete relationship: A tripartite efficacy perspective. The Sport Psychologist, 23, 203-232.

Keating, X. D., Guan, J., Piñero, J. C., \& Bridges, D. M. (2005). A meta-analysis of college students’ physical activity behaviors. Journal of American College Health, 54, 116-125. doi: 10.3200/JACH.54.2.116-126

Kenny, D. A., \& Acitelli, L. K. (2001). Accuracy and bias in perceptions of the partner in close relationships. Journal of Personality and Social Psychology, 80, 439-448. doi: 10.1037/ 0022-3514.80.3.439 
Running head: TRIPARTITE EFFICACY

1 Lent, R. W. \& Lopez, F. G. (2002). Cognitive ties that bind: A tripartite view of efficacy beliefs in growth-promoting relationships. Journal of Social \& Clinical Psychology, 21, 256-286. doi: 10.1521/jscp.21.3.256.22535

Lodewyk, K. R., Gammage, K. L., \& Sullivan, P. J. (2009). Relations among body size discrepancy, gender, and indices of motivation and achievement in high school physical education. Journal of Teaching in Physical Education, 28, 362-377.

Lyubomirsky, S., King, L. A., \& Diener, E. (2005). The benefits of frequent positive affect: Does happiness lead to success? Psychological Bulletin, 131, 803-855. doi: 10.1037/00332909.131.6.803

MacKinnon, D. P. (2008). Introduction to statistical mediation analysis. New York: Psychology Press.

Marsh, H. W., Hau, K. T. \& Wen, Z. (2004). In search of golden rules: Comment on hypothesis testing approaches to setting cutoff values for fit indexes and dangers in overgeneralizing Hu \& Bentler’s (1999) findings. Structural Equation Modeling, 11, 320-341. doi: 10.1207/ s15328007sem1103_2

McAuley, E., Duncan, T., \& Tammen, V. V. (1989). Psychometric properties of the intrinsic motivation inventory in a competitive sport setting: A confirmatory factor analysis. Research Quarterly for Exercise and Sport, 60, 48-58.

Myers, N. D., Feltz, D. L., \& Wolfe, E. W. (2008). A confirmatory study of rating scale category effectiveness for the coaching efficacy scale. Research Quarterly for Exercise and Sport, 79, 300-311.

Myers, N.D., Wolfe, E.W., \& Feltz, D.L. (2005). An evaluation of the psychometric properties of the coaching efficacy scale for coaches from United States of America. Measurement in Physical Education and Exercise Science, 9, 135-160. doi: 10.1207/s15327841mpee0903_1

Muthén, L. K., \& Muthén, B. O. (1998-2010). Mplus User’s Guide (6th ed.). Los Angeles, CA: Muthén \& Muthén. 
1 Pekrun, R., Goetz, T., \& Frenzel, A. C. (2005). Academic Emotions Questionnaire-Mathematics (AEQ-M) - User's Manual. University of Munich: Department of Psychology.

Pekrun, R., Goetz, T., Titz, W, \& Perry, R. P. (2002). Academic emotions in students’ selfregulated learning and achievement: A program of quantitative and qualitative research. Educational Psychologist, 37, 91-106. doi: 10.1207/S15326985EP3702

Rosenthal, R., \& Jacobson, L. (1968). Pygmalion in the classroom. New York: Holt, Rinehart \& Winston.

Ruthig, J. C., Perry, R. P., Hladkyj, S., Hall, N. C., Pekrun, R., \& Chipperfield, J. G. (2008). Perceived control and emotions: Interactive effects on performance in achievement settings. Social Psychology of Education, 11, 161-180. doi: 10.1007/s11218-007-9040-0

Ryan, R. M. (1982). Control and information in the intrapersonal sphere: An extension of cognitive evaluation theory. Journal of Personality and Social Psychology, 43, 450-461. doi: 10.1037/0022-3514.43.3.450

Taylor, I. M., \& Lonsdale, C. (2010). Cultural differences in the relationships among autonomy support, psychological need satisfaction, subjective vitality, and effort in British and Chinese physical education. Journal of Sport \& Exercise Psychology, 32, 655-673.

Theodorakis, Y. (1995). Effects of self-efficacy, satisfaction, and personal goals on swimming performance. The Sport Psychologist, 9, 245-253.

Trouilloud, D. O., Sarrazin, P. G., Martinek, T. J., \& Guillet, E. (2002). The influence of teacher expectations on students’ achievement in physical education classes: Pygmalion revisited. European Journal of Social Psychology, 32, 591-607. doi: 10.1002/ejsp.109

Tschannen-Moran, M., \& Woolfolk Hoy, A. (2001). Teacher efficacy: Capturing an elusive construct. Teaching and Teacher Education, 17, 783-805. doi: 10.1016/S0742051X(01)00036-1 


\section{Figure Captions}

Figure 1. Hypothesized relationships between students’ tripartite efficacy perceptions and physical activity class outcomes (i.e., effort, enjoyment, achievement). All relationships were forecasted to be positive in nature. RISE = relation-inferred self-efficacy.

Figure 2. Direct relationships between students' tripartite efficacy perceptions and physical activity class outcomes (i.e., effort, enjoyment, achievement). Values above/below arrows represent standardized path coefficients. Adjacent values in parentheses represent unstandardized estimates. $R^{2}$ coefficients are presented in italics above exogenous variables. Indicators were included in the specified model, but are excluded from the figure for clarity. RISE = relationinferred self-efficacy. $* * * p<.001, * * p<.01, * p<.05,{ }^{\dagger} p=.066$. 
Table 1. Descriptive statistics, alpha coefficients, and zero-order correlations

\begin{tabular}{lccccccccc}
\hline Variable & $M$ & $S D$ & $H$ & 1 & 2 & 3 & 4 & 5 & 6 \\
\hline 1. Self-efficacy & 3.93 & .50 & .89 & -- & & & & \\
2. Other-efficacy & 4.14 & .72 & .96 & .56 & -- & & & \\
3. RISE & 3.95 & .55 & .93 & .73 & .59 & -- & & \\
4. Enjoyment & 3.75 & .78 & .95 & .52 & .72 & .49 & -- & \\
5. Effort & 5.27 & 1.01 & .90 & .56 & .64 & .52 & .66 & -- & \\
6. Achievement & 66.80 & 9.49 & -- & .36 & .51 & .39 & .49 & .36 & -- \\
\hline
\end{tabular}

Note. All correlations significant at $p<.001$. RISE = relation-inferred self-efficacy. Self-efficacy, other-efficacy, RISE, and enjoyment measured from $1-5$, and effort from 1-7, where higher scores represent more positive perceptions. 
Table 2. Total and specific indirect effects for tripartite efficacy constructs

\begin{tabular}{|c|c|c|c|c|c|c|}
\hline \multirow[b]{2}{*}{ Effect } & \multicolumn{3}{|c|}{ Standardized } & \multicolumn{3}{|c|}{ Unstandardized } \\
\hline & Estimate & $\mathrm{SE}$ & $p$ & Estimate & SE & $p$ \\
\hline \multicolumn{7}{|l|}{ Total indirect effects } \\
\hline S-E $\rightarrow$ Ach & .04 & .04 & .38 & .47 & .52 & .37 \\
\hline $\mathrm{O}-\mathrm{E} \rightarrow$ Ach & .20 & .05 & $<.001$ & 2.24 & .55 & $<.001$ \\
\hline $\mathrm{RISE} \rightarrow$ Ach & -.05 & .05 & .28 & -0.66 & .62 & .29 \\
\hline \multicolumn{7}{|l|}{ Specific indirect effects } \\
\hline S-E $\rightarrow$ Enj $\rightarrow$ Ach & .09 & .03 & $<.01$ & 1.12 & .41 & $<.01$ \\
\hline $\mathrm{S}-\mathrm{E} \rightarrow \mathrm{Eff} \rightarrow$ Ach & -.05 & .03 & .12 & -.65 & .42 & .12 \\
\hline $\mathrm{O}-\mathrm{E} \rightarrow \mathrm{S}-\mathrm{E} \rightarrow \mathrm{Enj}$ & .05 & .02 & .02 & .05 & .02 & .02 \\
\hline $\mathrm{O}-\mathrm{E} \rightarrow \mathrm{S}-\mathrm{E} \rightarrow \mathrm{Eff}$ & .08 & .03 & $<.01$ & .08 & .03 & $<.01$ \\
\hline $\mathrm{O}-\mathrm{E} \rightarrow \mathrm{S}-\mathrm{E} \rightarrow$ Ach & -.01 & .02 & .46 & -.14 & .19 & .46 \\
\hline $\mathrm{O}-\mathrm{E} \rightarrow \mathrm{Enj} \rightarrow$ Ach & .27 & .05 & $<.001$ & 2.96 & .61 & $<.001$ \\
\hline $\mathrm{O}-\mathrm{E} \rightarrow \mathrm{Eff} \rightarrow$ Ach & -.06 & .04 & .10 & -.66 & .41 & .11 \\
\hline $\mathrm{O}-\mathrm{E} \rightarrow \mathrm{S}-\mathrm{E} \rightarrow \mathrm{Enj} \rightarrow$ Ach & .02 & .01 & .03 & .20 & .09 & .04 \\
\hline $\mathrm{O}-\mathrm{E} \rightarrow \mathrm{S}-\mathrm{E} \rightarrow \mathrm{Eff} \rightarrow$ Ach & -.01 & .01 & .15 & -.11 & .08 & .15 \\
\hline $\mathrm{RISE} \rightarrow \mathrm{S}-\mathrm{E} \rightarrow$ Enj & .16 & .06 & .01 & .19 & .07 & .01 \\
\hline $\mathrm{RISE} \rightarrow \mathrm{S}-\mathrm{E} \rightarrow$ Eff & .29 & .05 & $<.001$ & .32 & .06 & $<.001$ \\
\hline $\mathrm{RISE} \rightarrow \mathrm{S}-\mathrm{E} \rightarrow$ Ach & -.04 & .05 & .39 & -.58 & .65 & .39 \\
\hline RISE $\rightarrow$ Enj $\rightarrow$ Ach & -.04 & .03 & .18 & -.50 & .38 & .18 \\
\hline RISE $\rightarrow$ Eff $\rightarrow$ Ach & .01 & .01 & .44 & .08 & .10 & .45 \\
\hline $\mathrm{RISE} \rightarrow \mathrm{S}-\mathrm{E} \rightarrow \mathrm{Enj} \rightarrow$ Ach & .06 & .02 & $<.01$ & .76 & .29 & $<.01$ \\
\hline $\mathrm{RISE} \rightarrow \mathrm{S}-\mathrm{E} \rightarrow \mathrm{Eff} \rightarrow$ Ach & -.04 & .02 & .12 & -.44 & .28 & .12 \\
\hline
\end{tabular}

Note. S-E = self-efficacy; O-E = other-efficacy; RISE = relation-inferred self-efficacy; Enj = enjoyment; Eff = effort; Ach = achievement. 


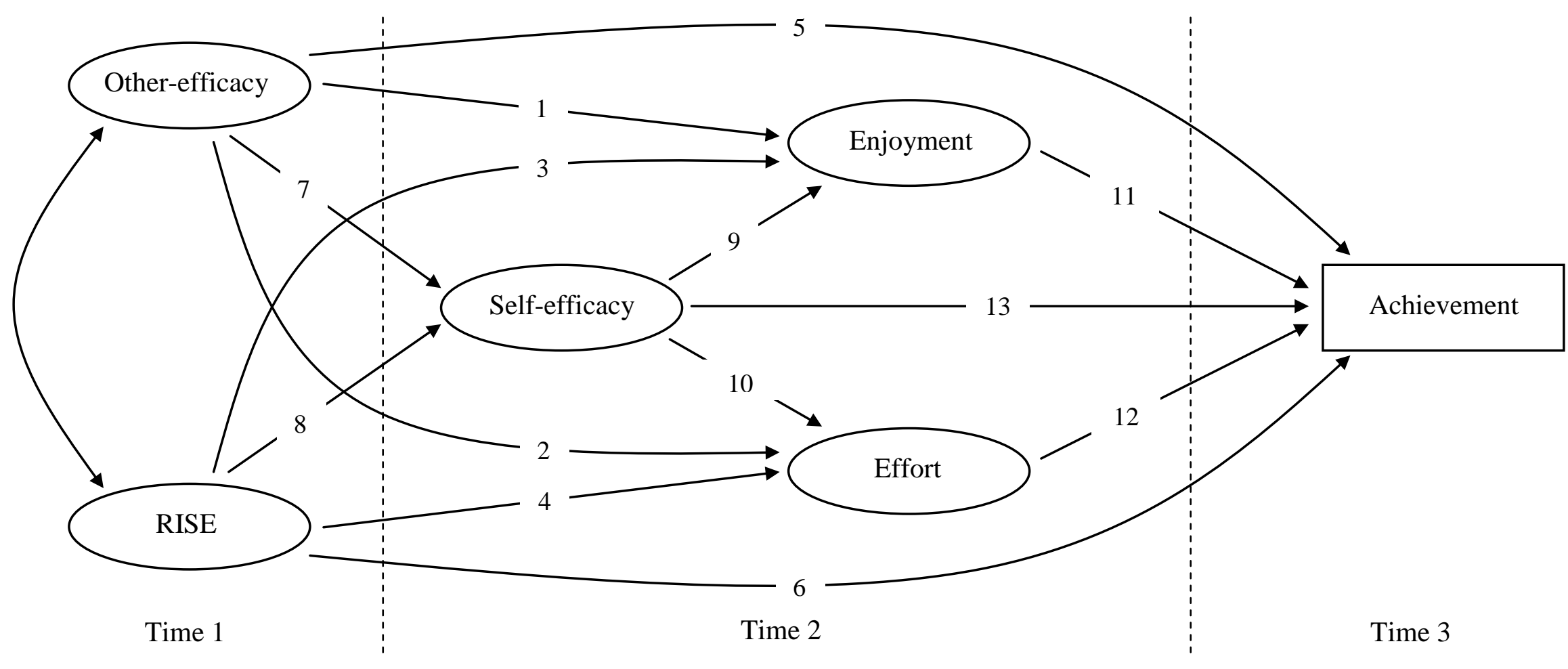




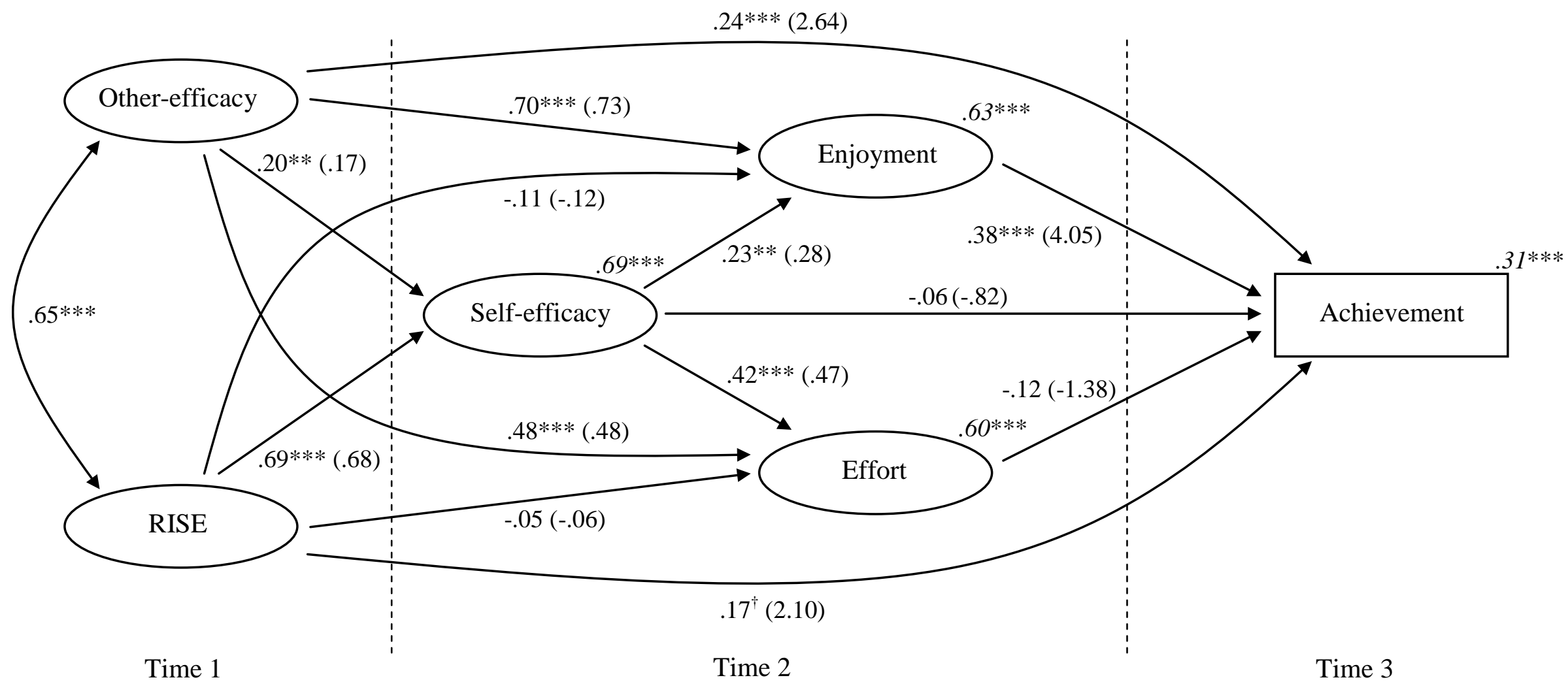

